Research Paper

\title{
Evolution of fabric anisotropy of granular soils: x-ray tomography measurements and theoretical modelling
}

\author{
Chao-Fa Zhao ${ }^{\mathrm{a}}$, Gustavo Pinzón ${ }^{\mathrm{b}}$, Max Wiebicke ${ }^{\mathrm{c}}$, Edward Andò ${ }^{\mathrm{b}}$, Niels P. Kruyt ${ }^{\mathrm{a}}$, \\ Gioacchino Viggiani ${ }^{\text {b, * }}$ \\ ${ }^{a}$ Department of Mechanical Engineering, University of Twente, P.O. Box 217, 7500 AE Enschede, the Netherlands \\ ${ }^{\mathrm{b}}$ Univ. Grenoble Alpes, Grenoble INP, CNRS, 3SR, F-38000 Grenoble, France \\ ${ }^{\mathrm{c}}$ Institut für Geotechnik, Technische Universität Dresden, D-01062 Dresden, Germany
}

\section{A R T I C L E I N F O}

\section{Keywords:}

Granular soils

Fabric anisotropy

Shear band

x-ray tomography

Anisotropic critical state theory

\begin{abstract}
A B S T R A C T
Fabric anisotropy is a key component to understand the behaviour of granular soils. In general, experimental data on fabric anisotropy for real granular soils are very limited, especially in the critical state. In this paper, $\mathrm{x}$ ray tomography measurements are used to provide experimental data on contact fabric anisotropy inside shear bands for two granular soils. The data are then used to assess the validity of Anisotropic Critical State Theory (ACST) and the accuracy of a fabric evolution law that was previously developed from the results of DEM simulations on idealised materials. Overall, the experimental results support ACST according to which unique ( $i$. e., independent of initial conditions) values for fabric anisotropy and coordination number are observed at large strains. With increasing roundness of the material, the rate at which the critical state is approached increases. The evolution of fabric anisotropy measured from the experiments is fairly well reproduced by the proposed evolution law.
\end{abstract}

\section{Introduction}

Granular soils are composed of solid particles and interparticle voids that are filled with one or more fluids. The arrangement of particles and voids involves the distribution of their sizes and orientations. Furthermore, it is important (for the force transmission) which particles are in contact. The microstructure includes the arrangement of particles, voids and interparticle contacts. This microstructure has a significant influence on the behaviour of granular soils, in particular on the shear strength and dilatancy, as has been shown by experiments (Yoshimine et al., 1998; Yang et al., 2007; Fonseca et al., 2013), micromechanical studies (Reynolds, 1885; Rowe, 1962; Rothenburg and Bathurst, 1989; Li and Dafalias, 2000; Kruyt, 2003; Yang et al., 2008; Li and Li, 2009; Yang et al., 2013; Li, 2016; Kruyt and Rothenburg, 2016; Kruyt and Rothenburg, 2019) and Discrete Element Method (as proposed in Cundall and Strack, 1979; DEM for short) simulations (Thornton and Barnes, 1986; Chantawarangul, 1993; Kruyt, 2012; Fu and Dafalias, 2015; Shi and Guo, 2018; Shi et al., 2018; Wang et al., 2019; Wang et al., 2020). To quantify the microstructure, a second-order fabric tensor (Oda, 1972; Satake, 1978; Oda et al., 1982; Oda, 1982; Oda and Nakayama, 1988;
Kanatani, 1984; Li and Li, 2009; Kruyt, 2012; Fu and Dafalias, 2015; Li, 2016; Kruyt, 2003; Wan and Pouragha, 2015; Shi and Guo, 2018) is usually employed, whose deviatoric part has been generally used to describe fabric anisotropy of granular soils. Various fabric tensors have been defined in the literature (Oda, 1972; Li and Li, 2009; Cambou et al., 2013), that differ in the involved micro-scale quantities. The description of the microstructure is based either on particle orientations (Oda, 1972 ), or on orientation vectors $\mathbf{u}^{c}$ associated with the interparticle contacts $c$ (Kruyt, 2012; Wang et al., 2017), or (less frequently) on the orientation of the voids (Tsuchikura and Satake, 2001; Nguyen et al., 2009; Li and Li, 2009).

Examples of such micro-scale vectors $\mathbf{u}^{c}$ are: (i) the vector normal to the contact plane (here referred to as contact normal) (Oda, 1982), (ii) the branch vector (Christoffersen et al., 1981, 1997, 1996) and (iii) the void vector (Tsuchikura and Satake, 2001; Nguyen et al., 2009; Li and Li, 2009). In this study, a fabric tensor based on interparticle contacts is considered, which is attractive since force transmission occurs at contacts.

The definition of a symmetric second-order fabric tensor $\mathbf{G}$ is based on the micro-scale vectors $\mathbf{u}^{c}$

\footnotetext{
* Corresponding author.

E-mail address: cino.viggiani@3sr-grenoble.fr (G. Viggiani).
} 
$\mathbf{G}=\frac{1}{N_{\mathrm{c}}} \sum_{c=1}^{N_{\mathrm{c}}} \mathbf{u}^{c} \otimes \mathbf{u}^{c} \quad \mathbf{F}=\frac{5}{2(1+e)}(3 \mathbf{G}-\mathbf{I})$,

where $N_{\mathrm{c}}$ is the total number of contacts and $e$ is the void ratio of the volume under consideration. Hence the fabric tensor $\mathbf{G}$ is an average of (the dyadic product of) the vectors $\mathbf{u}^{c}$ that are associated with interparticle contacts. The dimensionless fabric anisotropy tensor $\mathbf{F}$ in Eq. (1) (right), that is studied in the following and that has been widely used in the literature (Zhao and Guo, 2013; Yang et al., 2018), is proportional to the deviatoric part of the fabric tensor $\mathbf{G}$. Note that $\mathbf{F}$ is scaled with the specific volume, as suggested in Li and Dafalias (2015). The (scalar) norm $F$, termed as fabric anisotropy, and the direction tensor $\mathbf{n}_{F}$ of the fabric tensor $\mathbf{F}$ are defined by

$F=\sqrt{\mathbf{F}: \mathbf{F}} \quad \mathbf{F}=F \mathbf{n}_{F}$.

The direction tensor $\mathbf{n}_{F}$ satisfies $\mathbf{n}_{F}: \mathbf{n}_{F}=1$ and $\operatorname{tr}\left(\mathbf{n}_{F}\right)=0$. The relationship between continuum, macro-scale shear strength, and microscale interparticle forces is quantitatively expressed by the stressforce-fabric relationship (Rothenburg and Bathurst, 1989; Rothenburg and Bathurst, 1993; Mirghasemi et al., 1995; Nübel and Rothenburg, 1996; Ouadfel and Rothenburg, 2001; Li and Yu, 2013; Li and Yu, 2014) that also involves fabric anisotropy. Analogously, the strain-displacement-fabric relationship quantitatively expresses the relationship between continuum, macro-scale dilatancy rate, and micro-scale, interparticle deformation (Kruyt and Rothenburg, 2019).

In order to understand the evolution of fabric in granular soils under loading, three aspects are important: (1) inherent, initial anisotropy, (2) fabric evolution, and (3) fabric at the critical state (Yang et al., 2018; Zhao and Kruyt, 2020).

Since the fabric is important to the behaviour of granular soils, it may be expedient to include a fabric tensor into continuum-mechanical models (Pietruszczak and Pande, 2001; Woo and Salgado, 2015; Gao et al., 2014; Gao and Zhao, 2017; Yang et al., 2018; Petalas et al., 2019a, b). Then a fabric evolution law is required. Fabric evolution laws can be categorised with respect to the variables considered to be relevant for the fabric rate: (i) stress ratio rate, current fabric tensor, and void ratio (Wan and Guo, 2004; Lashkari and Latifi, 2008); (ii) (plastic) strain rate, current fabric tensor and void ratio (Sun and Sundaresan, 2011; Fang et al., 2019; Zhao and Kruyt, 2020); (iii) (plastic) strain rate as well as stress ratio rate, current stress and fabric tensors and void ratio (Tian and Yao, 2018; Yuan et al., 2019; Woo and Salgado, 2015; Zhao and Kruyt, 2020); and (iv) a plastic loading index, and the current fabric tensor (Li and Dafalias, 2011; Yang et al., 2018; Gao et al., 2014; Gao and Zhao, 2017; Nemat-Nasser, 2000; Woo and Salgado, 2015; Petalas et al., 2019a).

According to the classical Critical State Theory (CST for short) (Roscoe et al., 1958; Schofield and Wroth, 1968), for large deformations a granular material continues deforming under shear at constant stress and void ratio. This state is generally considered to be unique, i.e., independent of the initial state of the material. The uniqueness of the fabric anisotropy in this critical state (Roscoe et al., 1958; Schofield and Wroth, 1968) has long been controversial. Recently, results of DEM simulations have shown that fabric anisotropy approaches asymptotic unique values (Chantawarangul, 1993; Fu and Dafalias, 2011; Zhao and Guo, 2013; Kruyt and Rothenburg, 2014; Kruyt and Rothenburg, 2016; Yang and Wu, 2016; Wang et al., 2020). Li and Dafalias (2011) extended CST in their Anisotropic Critical State Theory (ACST for short) framework, according to which the stress ratio $\eta=q / p$, where $q$ is the deviatoric stress and $p$ is the mean stress, the void ratio $e$ and the fabric anisotropy $F$ (defined in Eq. (2)) of granular soils must satisfy the following conditions for large deformations:

$\eta=\eta_{c}=M \quad e=e_{c}(p) \quad F=F_{c}$.

The last additional condition forms the extension of ACST over CST.
ACST was initially motivated by observations of results of DEM simulations, and has been theoretically related to Gibbs stability condition ( Li and Dafalias, 2011).

Coordination number, i.e., the average number of contacts per particle, is readily quantified from results of DEM simulations. Such simulations indicate that at large deformations a critical coordination number is attained (i.e., a steady value that is independent of the initial conditions, such as void ratio) (Rothenburg and Kruyt, 2004; Barreto and O'Sullivan, 2012; Kruyt and Rothenburg, 2014). To the best of our knowledge, however, experimental results for granular soils on the evolution of coordination number have not been reported in the literature.

DEM simulations have been employed to study the effect of fabric on the behaviour of granular soils. Generally, the particles in such simulations correspond to spheres or 'clumps' consisting of several spherical particles (although more sophisticated shape descriptions exist such as (Nadimi and Fonseca, 2018; Kawamoto et al., 2018; Karapiperis et al., 2020)). Furthermore, simplified (Coulomb friction type) contact laws are adopted (Chantawarangul, 1993; Yang and Wu, 2016; Zhao and Guo, 2013). Although DEM simulations provide very detailed information on particle positions and displacements as well as interparticle forces, these idealisations are rather different from granular soils that have various shapes, surface roughnesses and interparticle contact laws.

With such DEM simulations, samples with various inherent anisotropy can be generated by gravity deposition or by the radius expansion method, and the evolution of fabric can be quantitatively determined, see for instance (Fu and Dafalias, 2011; Zhao and Guo, 2013; Kruyt and Rothenburg, 2014, 2016; Yang and Wu, 2016; Huang et al., 2014). The DEM simulation results show that inherent fabric anisotropy, initial void ratio and loading direction have a significant influence on the behaviour of granular soils (Chantawarangul, 1993; Yang and Wu, 2016; Zhao and Guo, 2013; Zhao and Kruyt, 2020; Wang et al., 2020).

Experimental studies on fabric of granular systems initially focused on the effect of inherent anisotropy on the macroscopic stress-strain response, where the initial orientation of the particles was controlled, and the macroscopic response was measured. Results of hollow cylinder torsion tests (Yoshimine et al., 1998; Nakata et al., 1998; Yang et al., 2007), plane strain tests (Oda et al., 1978; Tatsuoka et al., 1990; Lam and Tatsuoka, 1988) and triaxial compression and extension tests (Oda et al., 1978; Lam and Tatsuoka, 1988) demonstrated that the initial fabric strongly affects the overall, macroscopic stress-strain behaviour.

Although these results have shown the importance of fabric to the behaviour of granular systems, quantitative measurements of fabric evolution within samples were not feasible. Through the use of twodimensional assemblies, in combination with experimental techniques such as photoelasticity (Drescher and de Josselin de Jong, 1972; Oda et al., 1985) and stereophotogrammetry (Calvetti et al., 1997), the evolution of fabric within the sample under several loading paths was measured.

For three-dimensional systems, $\mathrm{x}$-ray tomography imaging (see Viggiani and Tengattini, 2019 and the references cited therein) is an ideal tool to measure the evolution of material fabric (particle orientation fabric, contact fabric, branch vector fabric), since it allows for the generation of a complete three-dimensional representation of the specimen at any point during the test. Nonetheless, retrieving contact fabric with $\mathrm{x}$ ray tomography presents several technical challenges, especially with respect to the detection of interparticle contacts (Wiebicke et al., 2017; Andò and Viggiani, 2018).

A recent x-ray tomography study (Imseeh et al., 2018) considered the effect of the initial void ratio of the sample and of the confining pressure. The evolution of contact-normal fabric (where $\boldsymbol{u}^{c}$ in Eq. (1) equals the vector $\boldsymbol{n}^{c}$ normal to the contact plane) anisotropy of four different granular materials was measured, where the fabric of the whole sample was quantified. It was found that initial void ratio, confining pressure and particle morphology greatly affect the evolution of fabric anisotropy. At large deformations, the experimental results show that fabric 
anisotropy approaches a constant value, possibly a critical state value. However, samples generally become heterogeneous due to the emergence of shear bands (i.e.,regions where shear strains localise), and inside them higher strains are achieved, compared to the outside (Desrues et al., 1996). This implies that fabric inside shear bands may approach critical state conditions, even for smaller strains of the whole sample. To assess the validity of the ACST framework, it is therefore important to experimentally study fabric evolution inside shear bands.

The evolution of contact fabric inside shear bands was first studied in Wiebicke et al. (2020) for samples of angular Hostun sand and round Caicos ooids. Using an observation window inside the shear band, as well as an observation window outside of the shear band, contact fabric was measured at several axial deformation levels. Before the beginning of the localisation process, contact fabric behaves similarly in both windows, while it significantly differs once the shear band emerges. The general results for both samples are similar, presenting a difference in anisotropy values and rate of change, indicating the influence of particle shape and interparticle friction.

To describe the evolution of fabric, a rate-form evolution law for the fabric tensor has recently been proposed by Zhao and Kruyt (2020), based on DEM simulation results from the literature. This evolution law involves critical-state fabric anisotropy, current fabric, stress ratio, loading direction and rate of deviatoric plastic strain. The influence of void ratio is accounted for through the state parameter (Been and Jefferies, 1985). This fabric evolution law is consistent with ACST and has been validated with results of DEM simulations on idealised materials, showing both hardening and softening behaviour and properly describing the influence of the initial void ratio. Therefore, it is important to assess its accuracy in predicting fabric evolution of real granular materials.

Considering the limitations in previous studies described above, the objectives of this study are to (i): present X-ray tomography measurements (involving an additional value for the confining stress in comparison to Wiebicke et al., 2020) of the evolution of fabric anisotropy inside shear bands of Hostun sand and Caicos ooids and compare it with that outside shear bands; (ii) experimentally investigate the validity of ACST and (iii) assess the accuracy of the fabric evolution law by Zhao and Kruyt (2020) in predicting the measured fabric evolution of granular soils.

The outline of this paper is as follows. In Section 2, the x-ray tomography experiments performed for measuring the evolution of fabric anisotropy of granular soils under triaxial compression are presented. In Section 3, experimental results are shown. In Section 4, the capability of the evolution law in Zhao and Kruyt (2020) is investigated by modelling the measured evolution of fabric anisotropy inside shear bands. Section 5 discusses the contributions of this study and the open issues on this topic.

\section{2. x-ray tomography measurements of contact fabric anisotropy}

In this Section, the properties of the tested granular soils are described, and the methodologies are introduced that are employed for identifying grains, tracking them to measure local strain as well as quantifying the contact-normal based fabric tensor and its evolution.

\subsection{Tested materials, experimental setup and image analysis}

The experiments analysed in this study comprise triaxial compression tests on two different materials: Hostun sand and Caicos ooids. Caicos ooids are round calcitic, oolitic grains from Turks and Caicos islands with a mean diameter $D_{50}=420 \mu \mathrm{m}$, whereas Hostun sand consists of angular grains from the Rhône-Alpes region in France with $D_{50}=338 \mu \mathrm{m}$. All experiments are conducted on dry specimens that are prepared by pluviation into a thin latex membrane. They are carried out inside the x-ray scanner at Laboratoire 3SR in Grenoble (France), allowing for the acquisition of numerous $\mathrm{x}$-ray scans of the specimens during shearing. Axial compression is applied from below with a loading ram with a hemi-spherical cap, allowing the bottom platen of the specimen to rotate. Axial force and displacement are the only externallymeasured quantities, while volume changes are obtained directly by analysing the acquired images.

Sample sizes are set by optimising a trade-off between pixel-size (small sample) and field of view combined with the representativeness of the mechanical response (large sample) (Andò et al., 2013). The samples therefore have a relatively small size of $11 \mathrm{~mm}$ in diameter, 22 $\mathrm{mm}$ in height, and consist of more than 40,000 grains for Hostun sand samples, and more than 70,000 grains for Caicos ooids samples. The tomographies are acquired at a pixel size of $15 \mu \mathrm{m}$, which for example resolves the Hostun sand grains with 22.5 pixels across the average grain diameter. Table 1 presents a summary of the initial state for each sample. Details on the experiments HNMWTC02 and HNMWTC05 are given in Wiebicke (2020) and on HNEA01, COEA01 and COEA04 in Andò (2013). Additionally, the use of x-ray tomography allows for a complete $3 \mathrm{D}$ description of the shape of the particles using several indices, such as sphericity, roundness, and aspect ratio. Results for the two materials used here are given in Rorato et al. (2019).

During each test, the loading of the specimen is halted at chosen axial strain levels to perform $\mathrm{x}$-ray scans. The $3 \mathrm{D}$ grey-scale volumes, resulting from each x-ray scan, are used to identify and track each grain throughout the test. Firstly, the two phases within the sample, i.e., solid and void, are distinguished based on their grey level and a binary image is created. Subsequently, the binary image is segmented using a watershed algorithm (Beare and Lehmann, 2006) and each identified grain is labelled uniquely. Particle quantities, such as the centre of mass, volume, and orientation, can directly be computed from this labelled image.

The determination of the interparticle contacts is more complex and can be prone to errors. It follows the proposed technique from Wiebicke et al. (2017) (with a higher local threshold for Caicos to exclude overcounted contacts, since the problem is worse for flatter contacts). The contact normal orientations are then determined by performing an additional segmentation with the random walker (Grady, 2006) on each pair of contacting grains. The orientations are measured by performing a principal component analysis on the point cloud defining the contact zone. All image analyses are performed using the open-source software spam (Stamati et al., 2020).

\subsection{Quantifying fabric and fabric evolution}

Once the contacts $c$ have been detected and the associated contact orientation $\mathbf{n}^{c}$ have been obtained, the contact-normal based fabric tensor and its deviatoric part can be quantified by Eq. (1).

The required fabric input for the evolution law of Zhao and Kruyt (2020) is the fabric tensor inside the emerging shear band. Therefore, we

\section{Table 1}

Initial parameters of experimental samples, from Andò et al. (2013), Wiebicke (2020), and Andò (2013). The relative density of the Caicos ooids specimens could not be measured, due to the very limited amount of available material. Quantities in the last two columns are measured inside the region of the sample that will eventually become a shear band.

\begin{tabular}{|c|c|c|c|c|}
\hline Test ID & $\begin{array}{l}\text { Void Ratio } \\
\text { (relative } \\
\text { density) }\end{array}$ & $\begin{array}{c}\text { Confining } \\
\text { Pressure } \\
{[\mathrm{kPa}]}\end{array}$ & $\begin{array}{c}\text { Fabric } \\
\text { Anisotropy } \\
\text { (inside shear } \\
\text { band) }\end{array}$ & $\begin{array}{l}\text { Coordination } \\
\text { Number (inside } \\
\text { shear band) }\end{array}$ \\
\hline HNEA01 & $\begin{array}{l}0.658 \\
(83 \%)\end{array}$ & 100 & 0.299 & 6.25 \\
\hline HNMWTC02 & $\begin{array}{l}0.661 \\
(83 \%)\end{array}$ & 100 & 0.097 & 7.18 \\
\hline HNMWTC05 & $\begin{array}{l}0.655 \\
(85 \%)\end{array}$ & 400 & 0.166 & 7.14 \\
\hline COEA01 & $0.544(-)$ & 100 & 0.056 & 5.63 \\
\hline COEA04 & $0.610(-)$ & 100 & 0.135 & 5.23 \\
\hline
\end{tabular}


concentrate on the determination of contact fabric in the region of strain localisation. An analysis of the contact fabric of the experiments HNEA01 and COEA01 was already presented in Wiebicke et al. (2020). The fabric was extracted in two observation windows that are fixed in space: one inside the emerging shear band and one outside. Each window contains between 2800 and 4800 grains. Only results from these windows are presented in this study. Fig. 1 shows these two windows in a 3D rendering of Hostun sand specimen HNEA01 at large axial strain.

\subsection{Measurement of grain kinematics and local strain}

Using the labelled image as the definition of the grains in a given tomography volume, the displacement and rotation of each grain between images is measured with Discrete Digital Image/Volume Correlation, as first used in Hall et al. (2010) and implemented in the SPAM-DDIC script (see for example (Andò et al., 2019)). Concisely, this means that using the labelled image of each grain as a mask, the grey level from the reference image is extracted and an iterative procedure is used to seek the best transformation of the deformed image that minimises a sum-ofsquares residual function. The result of this discrete correlation is a transformation function for each label (i.e., grain) from the reference image, where labels are defined, to a given deformed image.

In this study, each image is labelled independently of the others and discrete correlation is performed with the next image, meaning that the granular displacement fields are incremental. Incremental local strains are obtained with Bagi's method (Bagi, 1996), which involves a Delaunay triangulation based on the grain centres. These local strains are explicitly required as (one of the) input to the model that will be used in Section 4, to predict the evolution of fabric anisotropy.

\section{Experimental results}

In this Section the experimental results, including the evolution of stress and void ratio (Section 3.1), the final morphology of the shear band (Section 3.2), fabric anisotropy (Section 3.3), and coordination number (Section 3.4) are examined in the light of the ACST. The evolution of void ratio and fabric anisotropy are presented in observation windows inside as well as outside the emerging shear bands.

\subsection{Stress ratio and void ratio}

The macroscopic response of the experiments on Hostun sand is plotted in Fig. 2(a), where the stress relaxation parts correspond to the points where the scans have been performed. Tests HNEA01 and HNMWTC02 are carried out at a cell pressure of $100 \mathrm{kPa}$, whereas test HNMWTC05 is conducted at $400 \mathrm{kPa}$. The experiments were performed
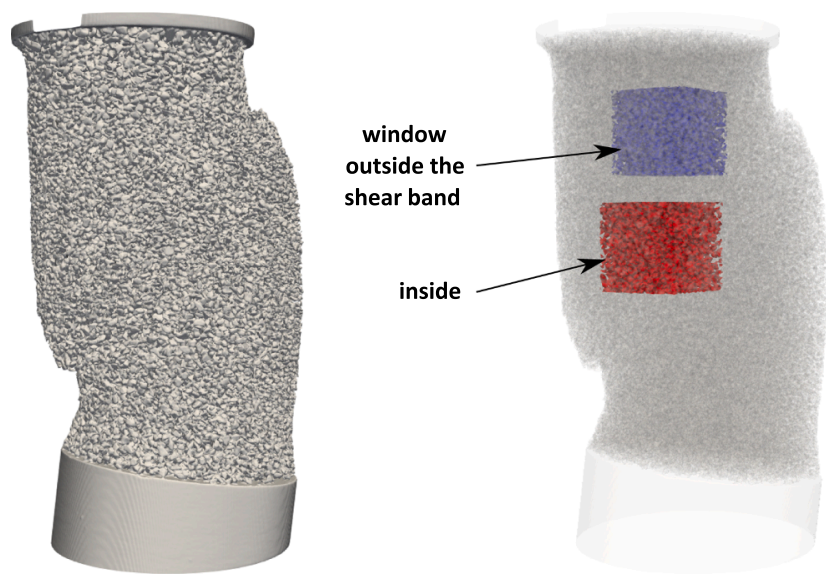

Fig. 1. Visualisation of the location of the observation windows in Hostun sand specimen (HNEA01) at large axial strain (after Wiebicke, 2020). by different experimenters and with a different purpose in mind. HNEA01 was purposefully sheared up to relatively large strain, to study strain localisation, whereas the latter two experiments included several load reversals as these tests are part of a study that focused on fabric evolution during cyclic loading (Wiebicke, 2020); these cycles will not be considered in this study, but are shown for completeness. Unfortunately, the continuous recording of force and displacement failed for test HNMWTC05, and only the macroscopic states at which the tomographies were acquired could be reconstructed. These are marked by the red points in the plot, which are simply connected to each other with dashed lines.

The stress ratio response of test HNEA01 differs substantially from that of the other two tests. HNEA01 shows a higher initial stiffness as well as an earlier peak of the stress ratio, although it is initially slightly denser than HNMWTC02 and is otherwise carried out with the same macroscopic boundary conditions. It has to be noted that the specimens also differ in the initial fabric, which may be responsible for the different macroscopic response. This will be elaborated in the corresponding section.

Since only the void ratio inside the emerging shear band is considered for the modelling in Section 4, the void ratios are computed in the same observation windows as the contact fabric. The evolution of void ratio with the macroscopic axial strain is plotted in Fig. $2(b)$ for the Hostun sand specimens. The results for the two observation windows show that the specimens start to behave heterogeneously at approximately $3 \%$ of macroscopic axial strain, which can be interpreted as the onset of strain localisation. From this value of axial strain, the void ratios in the windows diverge, i.e., the void ratio inside the shear band starts to increase whereas it either decreases or stays constant outside the emerging shear band. The void ratios in specimen HNEA01 are slightly higher than in the other two specimens, but follow a similar evolution. HNEA01 is also the only test that reaches a steady void ratio at the end of shearing.

Fig. 2(c) shows the evolution of the void ratios inside and outside the shear bands as a function of mean stress. As a reference, the critical state line of Hostun sand reported by Li (2013), which was obtained from conventional triaxial compression tests, is also plotted. This critical state line lies in between the final void ratios inside and outside of the shear band, which is understandable, since it represents a sample-wide average over regions with different levels of shear strain.

The macroscopic response obtained from two tests on Caicos ooids is shown in Fig. 3(a), and once again, the stress relaxation parts correspond to the points where the scans have been performed. The evolution of stress ratio in both samples is qualitatively similar: both curves exhibit a pronounced peak stress ratio before softening to a steady value. The only difference is the higher stress peak in test COEA01, which is likely due to the lower initial relative density (see Table 1). Qualitatively, void ratios inside and outside the emerging shear band show a similar evolution as for Hostun sand. The onset of strain localisation occurs earlier than for Hostun sand, between 1 and $2 \%$ global axial strain. Afterwards, the specimens dilate strongly inside the shear band, while void ratio stays constant, or slightly reduces outside the shear band. In both tests, a constant void ratio is reached at the end, which can be interpreted as the critical state - in fact, stress ratio is also constant at the end of the two tests. Note that this was also the case for test HNEA01, but not for the other two tests on Hostun sand, which were stopped at a lower axial strain.

\subsection{Shear band morphology}

The orientation and thickness of shear bands are known to depend on mean stress and particle shape. In order to explore the different shear band morphologies obtained in round Caicos ooids and angular Hostun sand, Fig. 4 shows the (vertical slices through the 3D) fields of particle rotations measured in the last increment of each test. Given that the rotation of the particles is a $3 \mathrm{D}$ vector, only the magnitude of the 

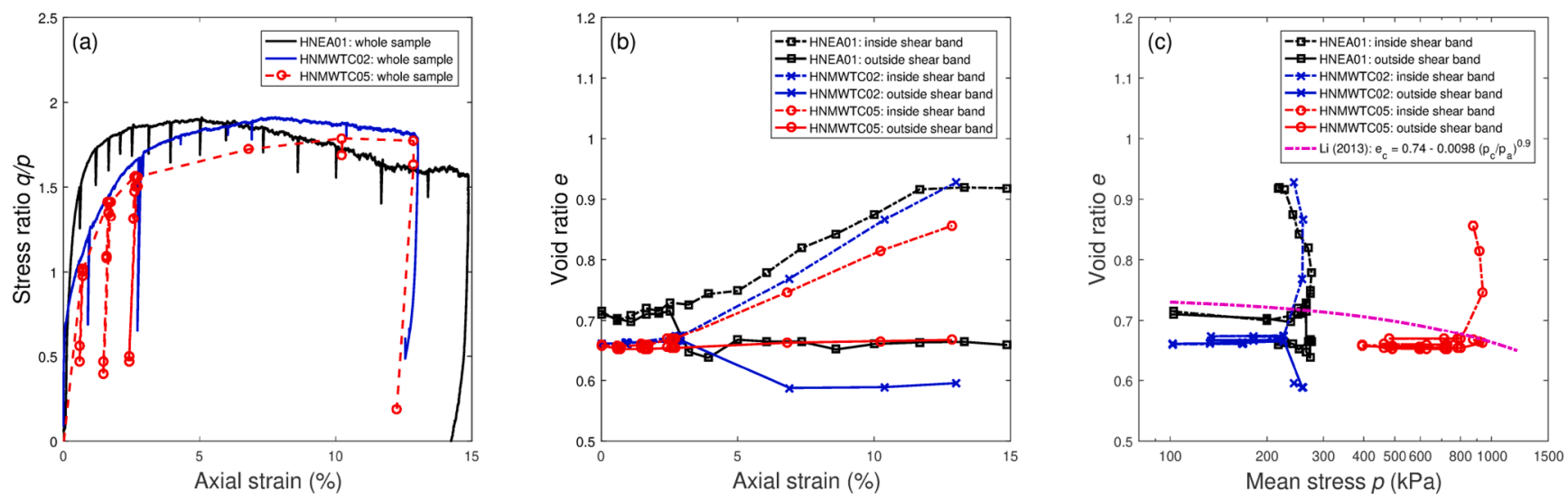

Fig. 2. Test results for Hostun sand: (a) evolution of stress ratio $\eta=q / p$ with global axial strain; (b) evolution of void ratio with global axial strain inside (dashed line) and outside (continuous line) the emerging shear band; (c) relation between void ratio and mean stress inside (dashed line) and outside (continuous line) the emerging shear band, and the critical state line from Li (2013).
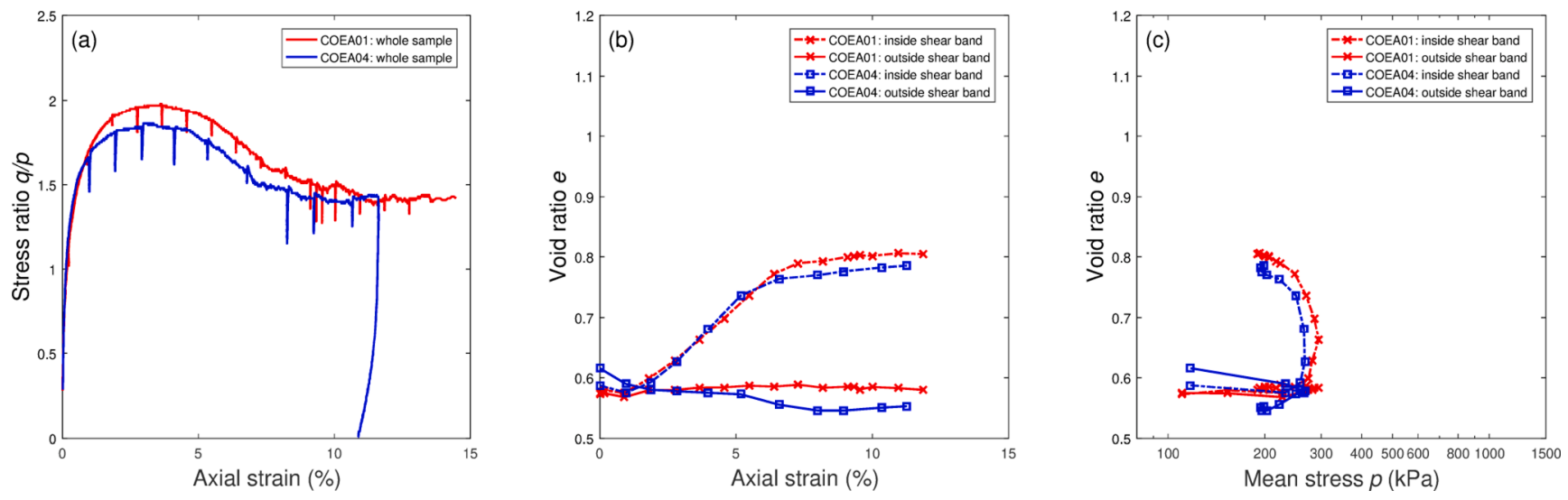

Fig. 3. Test results for Caicos ooids: (a) evolution of stress ratio with global axial strain; (b) evolution of void ratio with global axial strain inside (dashed line) and outside (continuous line) the emerging shear band; (c) relation between void ratio and mean stress inside (dashed line) and outside (continuous line) the emerging shear band.

COEA01

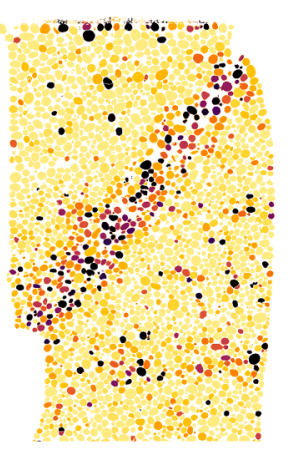

COEA04

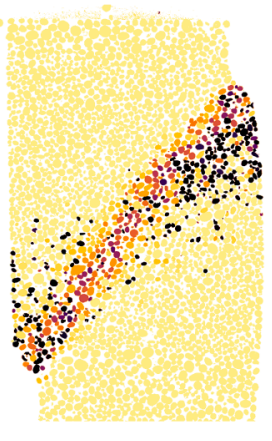

HNMWTCO2

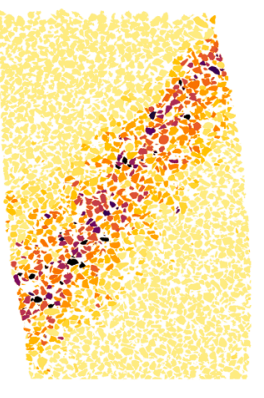

HNMWTCO5

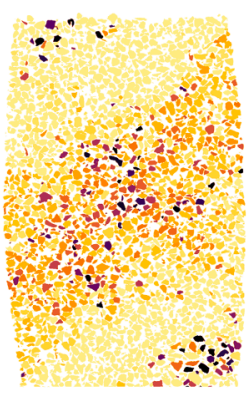

HNEA01

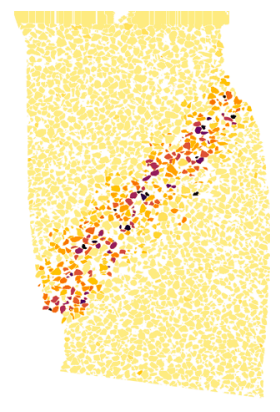

\section{Rotation angle}

$0^{\circ}$

Fig. 4. Magnitude of incremental 3D grain rotation vectors for the last increment in each test.

rotation is shown. Note that the axial strain level and the length of the selected axial strain increment vary from one test to another. For Hostun sand samples (HNEA01, HNMWTC02, and HNMWTC05), the axial strain at the beginning of the increment is $13.3 \%, 10.3 \%$, and $10.2 \%$, respectively, whereas the length of the axial strain increment is $1.5 \%$, $2.6 \%$, and $2.6 \%$, respectively. For the Caicos ooids samples (COEA01 and COEA04), the axial strain level at the beginning of the increment is $10.9 \%$ and $8.9 \%$, while the length of the axial strain increment is $0.9 \%$ 
and $1.3 \%$, respectively.

Clear differences can be observed from one test to another. Both samples of Caicos ooids present a well defined and established shear band, with a thickness of 8-10 times $D_{50}$; grain rotations inside the shear band are relatively large, with a mean rotation of $15^{\circ}$ and several particles rotating more than $25^{\circ}$. As for Hostun sand, in sample HNMWTC02 the shear band is $12-15$ times $D_{50}$ thick, with a mean rotation of $9^{\circ}$. In sample HNMWTC05, which was sheared at a confinement 4 times larger than HNMWTC02, grain rotations are less localised in space, i.e., the shear band is much thicker (15-20 times $D_{50}$ ) and the mean grain rotation is lower $\left(5^{\circ}\right)$. Interestingly, HNEA01 shows a narrow shear band with a width of 8-11 times $D_{50}$, similar to Caicos ooids, although with a lower mean rotation $\left(6^{\circ}\right)$. This narrower shear band in HNEA01, as compared to the other two tests on Hostun sand, is possibly related to the significantly higher initial value of fabric anisotropy (see Table 1), as will be discussed in the next section.

The inverse proportionality between the magnitude of the grain rotation and the width of the shear band can be explained due to the angularity of the particles and the interlocking potential between them (Andò et al., 2013). Angular grains (as Hostun sand) develop a highly interlocked structure, restricting the particles to low levels of rotation, while inducing secondary rotations of the surrounding grains - thus increasing the width of the shear band. Rounded grains (as Caicos ooids) on the other hand, can rotate more freely without significantly affecting adjacent particles - thus developing narrow shear bands and presenting higher particle rotation. Additionally, the relation between interlocking potential and grain rotation can be extended to understand the effect of the confining pressure. Sample HNMWTC05 is sheared at a higher confining pressure than HNMWTC02 and HNEA01, thus making grain rotation more difficult, which results in a wider shear band with lower magnitude of grain rotations, as shown in Fig. 4.

\subsection{Evolution of fabric anisotropy}

Fig. 5 shows the evolution of fabric anisotropy as defined in Eq. (2). The error in determining contact orientations that was quantified in Wiebicke et al. (2017) for Hostun sand and perfect spheres is propagated through Eqs. (1), (2) and shown as small error bars. These error bars are surprisingly small, as the fabric tensor smooths over thousands of orientations and only the determination of the orientation itself is considered. The true existence of a detected contact is not included in the uncertainty of the anisotropy. The error arising from falsely identified contacts is only mitigated by the measures developed in Wiebicke et al. (2017). Similarly to the void ratio, fabric anisotropy is measured in the observation windows inside and outside of the emerging shear band. In the experiments on Hostun sand, fabric anisotropy evolves similarly in both windows until the onset of strain localisation. Once a shear band forms, fabric anisotropy inside the shear band substantially increases, whereas it rapidly levels off outside the band. The only notable exception to the above is specimen HNMWTC05, where fabric anisotropy keeps increasing also outside of the shear band. The reason for this can be understood by looking at the much wider region of strain localization in this specimen (see Fig. 4); in these conditions, it is to be expected that fabric anisotropy evolves in the whole sample throughout the test. The increasing anisotropy is a result of the change in contact orientations. With ongoing shear, the orientations align with the major principal stress direction. This is caused partly by contacts being lost perpendicular to and gained in the direction of the loading. Most of the contacts, however, persist through the loading increments and change their orientation. The contact kinematics will be studied in detail elsewhere as they are not crucial for this work.

It is worth noting that in all tests the initial value of fabric anisotropy is the same in the two observation windows, which indicates the relative homogeneity of fabric in the specimen before shearing. Sample HNMWTC02 is the only exception, with a difference of about 0.1 between the initial values of anisotropy in the two windows. Interestingly, although fabric anisotropy is initially lower in the region that will eventually be inside the shear band, it increases during shearing, rapidly surpasses the value outside the shear band, and ends up reaching almost the same value as in test HNMWTC05. The fabric of a complete sample, however, is not necessarily as homogeneous as in these examples. Note that we only present the response for two observation windows within the specimens. For the initial state of specimen HNMWTC02 we identified variations of void ratio, coordination number and fabric anisotropy of roughly $\pm 0.025,0.25$ and 0.15 , respectively, in absolute values. This heterogeneity remains relatively constant until the onset of the shear band formation and increases drastically afterwards. Qualitatively, the response along the shear band is similar. Quantitatively, variations exist similarly to the measured heterogeneity of the initial state.

The contact fabric of specimen HNEA01 is substantially more anisotropic in the initial state, in comparison to all other specimens, see
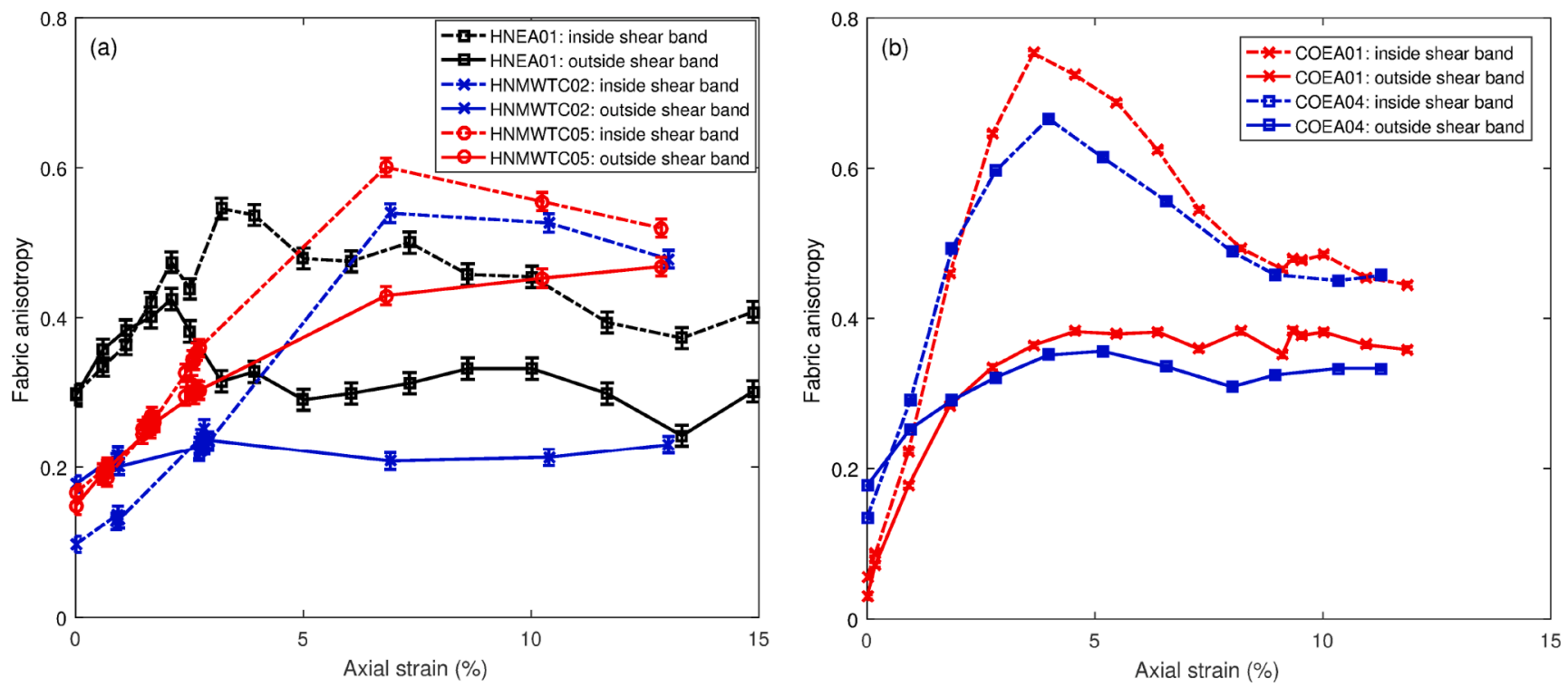

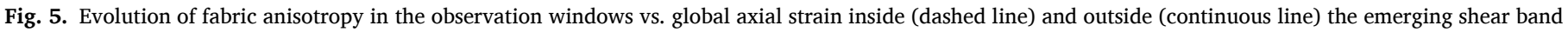
for (a) Hostun sand; (b) Caicos ooids. Note that fabric anisotropy is normalized by the specific volume of the measured volume as defined in Eqs. (1) and (2). 
also Table 1 . Similarly to the stress ratio, fabric anisotropy reaches its peak earlier than the other Hostun sand specimens and decreases afterwards to an approximately steady value of 0.45 . The high initial anisotropy arises from a strong preferential orientation of contact normals in the vertical direction, as visualised and discussed in Wiebicke (2020). This in turn means that the contacts are already aligned with the major principal stress direction and can thus sustain the applied loading. As the fabric in the other specimens is initially more isotropic, the contacts require more deformation to align with the loading direction. This can be the cause for the peak stress ratio being reached at a lower axial strain in test HNEA01.

The evolution of fabric anisotropy is very similar in the two Caicos ooids specimens. Inside the shear band, it increases until reaching a pronounced peak, and then decreases to a steady value. It is remarkable that fabric anisotropy inside the shear band follows the macroscopic stress ratio very closely, as already noted by Wiebicke et al. (2020). Similarly to the void ratio, the onset of strain localisation occurs at approximately $1 \%$ axial strain, considerably earlier than in the Hostun sand specimens. This is due to the round shape of the grains, which facilitates the emergence of a narrow shear band (Andò et al., 2013) when compared to the more angular Hostun sand grains. This is also the reason why Hostun sand samples reach a steady state later: angular grains cause interlocking, which hinders strain localisation and results in a wider shear band.

At large strains, fabric anisotropy inside the shear band tends to similar values for each of the two materials. However, the only Hostun sand specimen that possibly reaches a critical state (in that both stress ratio and void ratio level off, see Fig. $2(\boldsymbol{a}-\boldsymbol{b})$ ) is HNEA01. For the other two Hostun specimens, the void ratio does not reach a steady state at large axial strains (see Fig. 2(b)). Fabric anisotropy inside the shear band of HNEA01 reaches a steady value of approximately 0.45 , whereas the fabric anisotropies of the other specimens are still decreasing at the end of the test. It can be observed, however, that they seem to approach a similar value as HNEA01.

Both Caicos ooids specimens reach a critical state and show a similar fabric anisotropy of approximately 0.45 inside the shear band. Although the specimens initially have a different fabric anisotropy, they gradually evolve to the same fabric anisotropy inside the shear band at critical state, which is in agreement with the existence of a unique value of the critical state anisotropy within ACST.

Finally, it should be noted that the curves of fabric anisotropy $v s$.

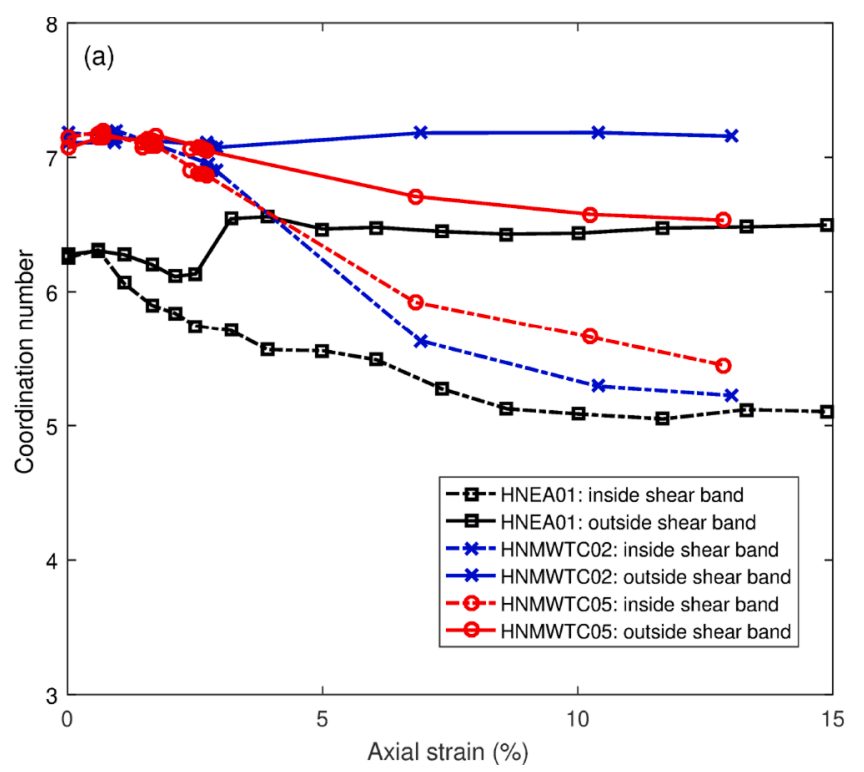

axial strain are much smoother for Caicos ooids than for Hostun sand. This is due to the higher accuracy with which contact orientations (and thus contact fabric) are measured for round grains as compared to angular grains (Wiebicke et al., 2017).

\subsection{Coordination number}

A simple, yet important quantity describing contacts is the coordination number, i.e., the number of contacts per particle. Although it is not used in the fabric evolution law proposed in Zhao and Kruyt (2020), we briefly present its evolution for completeness. The average coordination number $Z$ in a set of contacting particles is defined as

$Z=2 \frac{N_{c}}{N_{p}}$

with $N_{p}$ and $N_{c}$ being the total number of particles and contacts, respectively. The basis for the measurement of $Z$ is the detection of contacts, the accuracy of which depends on the shape of the particles (see Wiebicke et al., 2017; Wiebicke et al., 2019). However, the actual values of $Z$ are not necessarily relevant, and it is rather the qualitative evolution of the coordination number that matters.

The evolution of the coordination number inside and outside the shear band is shown in Fig. 6 for both Hostun sand and Caicos ooids. Hostun sand specimens HNMWTC02 and HNMWTC05 have a very similar initial $Z$, whereas HNEA01 has a lower initial coordination number (which is consistent with a higher initial void ratio, see Fig. 2(b)). After the onset of strain localisation, the coordination number strongly decreases inside the shear band, whereas it stays relatively constant outside. Similar to fabric anisotropy, the coordination number inside the shear band reaches a steady value at approximately $8 \%$ global axial strain for HNEA01. For the other two Hostun sand specimens, the evolution of $Z$ shows a tendency to slow down and tends towards a steady value at the end of the tests, although for these two tests the void ratio does not (Fig. 2(b)). In an earlier analysis (Wiebicke et al., 2020) of contact fabric evolution in two of the five tests analysed here, it was found that the evolution of $Z$ is more sensitive to changes in the local microstructure than that of void ratio. Therefore, it is reasonable to argue that HNMWTC02 and HNMWTC05 are in fact close to reaching a steady state inside the shear band.

For the Caicos ooids specimens, the coordination number evolves in a similar way in the two tests. After the onset of strain localisation, the

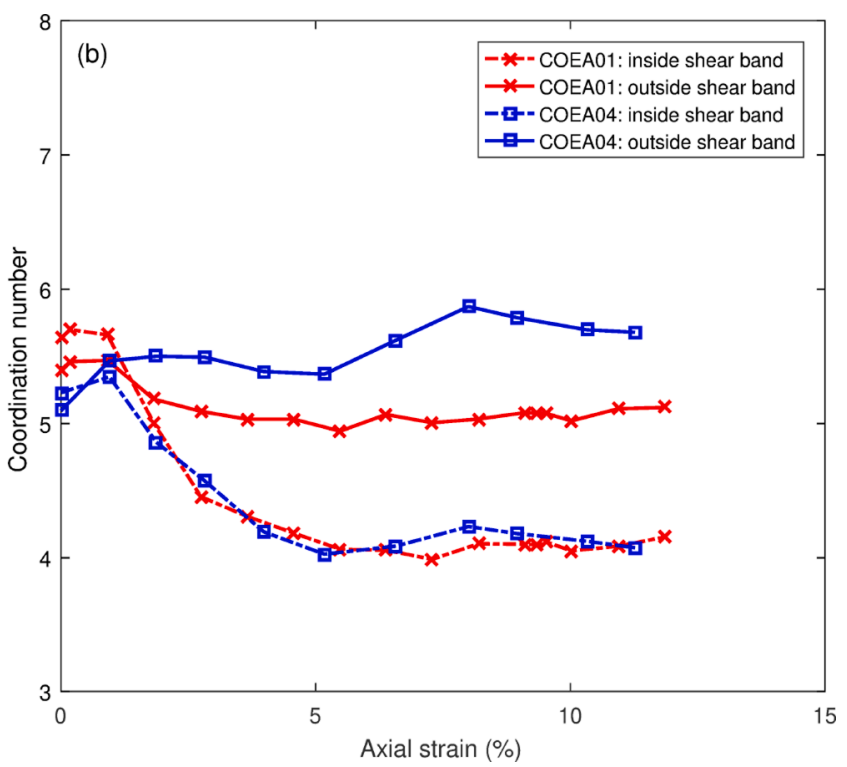

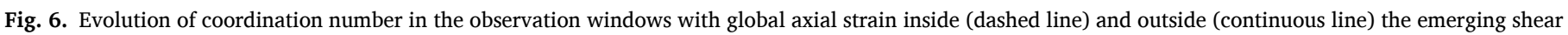
band for (a) Hostun sand; (b) Caicos ooids. 
coordination number inside the shear band decreases and rapidly reaches a steady value, whereas it stays constant or slightly increases outside. The initial value of $Z$ in specimen COEA04 is lower outside the shear band than inside, which also corresponds to a higher initial void ratio (see Fig. 3(b)). As already observed for contact fabric anisotropy, the coordination number reaches a steady and unique value at the end of the tests on Caicos ooids.

\subsection{Implications of experimental results for CST and ACST}

In this section, the experimental results presented above are analysed in the light of CST and ACST. According to CST, both stress ratio $q / p$ and void ratio $e$ should be unique (i.e., independent of initial conditions) at critical state. ACST brings the additional condition that also fabric anisotropy $F$ should be unique at critical state.

An important issue is whether the achieved strains inside the shear bands are sufficiently large for critical state conditions to be actually attained in the experiments. For Hostun sand, the only test in which the stress ratio $q / p$ becomes steady at the end of the test is HNEA01. At the end of the other two tests, the stress ratio is still slowly evolving (and higher than the final value in HNEA01). The samples HNMWTCO2 and HNMWTC05 are still dilating at the end of the test, while the void ratio has reached a steady state at the end of test HNEA01. In summary, the tests on Hostun sand are inconclusive with respect to the validity of CST. As for Caicos ooids, tests COEA01 and COEA0 4 show a clear steady state for both stress ratio $q / p$ and void ratio $e$ at the end of the test. The final value of the stress ratio is the same in the two tests. This is also the case for the final void ratio - although some slight differences are observed. Hence, these tests essentially conform to CST.

As far as the requirements of ACST are concerned, in the case of Hostun sand, a steady state for fabric anisotropy $F$ is attained only in test HNEA01, while $F$ is still evolving at the end of tests HNMWTC02 and HNMWTC05. It is possible that if larger strains were achieved, then the asymptotic fabric anisotropy in all these tests would be the same (as expected by ACST). It is interesting that similar trends are observed for the coordination number $Z$, which is another descriptor of microstructure. Note that the coordination number in test HNMWTC02 is smaller than in test HNMWTC05, due to the larger confining pressure. For Caicos ooids, fabric anisotropy in both tests reaches a clear steady state, with equal $F$ in both tests. The same qualitative result is obtained for the coordination number $Z$. Overall, the results for Caicos ooids clearly conform to ACST; those for Hostun sand appear to be compatible, but the achieved strains were insufficiently large to draw a strong conclusion.

\section{Modelling the evolution of fabric anisotropy inside shear bands}

In this section, the fabric evolution law developed in Zhao and Kruyt (2020) is employed to simulate the evolution of fabric anisotropy, for the two materials studied, and the predicted evolution is compared to the experimental results. In the interpretation of the experimental results, it is assumed that the plastic strain is equal to the total strain, which may not be appropriate outside the shear band where the plastic strains are smaller. Therefore, the evolution of fabric is only simulated inside the shear bands.

The fabric evolution law proposed in Zhao and Kruyt (2020) is summarised in Section 4.1. The determination of the model parameters is given in Section 4.2. The comparison of the evolution of fabric anisotropy between the experimental results and the model predictions is presented in Section 4.3.

\subsection{Fabric evolution law}

The adopted fabric evolution law is that developed in Zhao and Kruyt (2020), given by
$\dot{\mathbf{F}}=\mathbf{H}\left(\mathbf{F}, \theta_{s}, \eta, \psi, \dot{\epsilon}_{q}^{p}\right)=h\left\{F_{c}\left(\theta_{s}\right)-\mathbf{F}: \mathbf{n} \cdot \exp (m(M-\eta)+\psi)\right\} \dot{\epsilon}_{q}^{p}$

where $F_{c}$ is the critical-state fabric anisotropy (dependent on the Lode angle $\theta_{s}$ of the stress tensor), $\dot{\epsilon}_{q}^{p}$ is the deviatoric part of the plastic strain rate, the loading direction $\mathbf{n}$ is defined as $\mathbf{n} \equiv \frac{\dot{\epsilon}_{q}^{p}}{\left\|\dot{e}_{q}^{p}\right\|}, \eta$ and $M$ are the stress ratios defined in Eq. (3), and $h$ and $m$ are two model parameters. As described in Zhao and Kruyt (2020), the term $\mathbf{F}: \mathbf{n}$ represents the combined effect of the microstructure and loading direction. The state parameter $\psi$ is defined by $\psi=e-e_{c}(p)$ in Been and Jefferies (1985). For given mean effective stress $p$, the critical state void ratio $e_{c}=e_{c}(p)$ is estimated by

$e_{c}(p)=e_{\Gamma}-\xi\left(\frac{p}{p_{a}}\right)^{\alpha}$

where $e_{\Gamma}, \xi$ and $\alpha$ are dependent on the material; $p_{a}$ is the (reference) atmospheric pressure. The model parameters in the fabric evolution law involve well-established parameters (those in the critical state line and the critical state stress ratio $M$ ) as well as a small number of additional parameters $\left(F_{c}, h\right.$ and $\left.m\right)$.

Based on observations of results from DEM simulations in Yang and Wu (2016) and Zhao and Guo (2013) and experimental studies in Wiebicke et al. (2020) where the Lode angle of stress is constant, it is noted that at critical state, fabric and loading direction are coaxial. In Jiang et al. (2019) the loading direction was based on the stress tensor, and it was found that the contact normal fabric tensor always tends to be coaxial with the stress tensor under cyclic loading, regardless of the specimen density and cyclic failure mode. Therefore, at the critical state the condition $\mathbf{n}_{F}: \mathbf{n}=1$ holds for various loading conditions. In addition, at critical state the stress ratio $\eta$ attains its critical value $M$ and the state parameter $\psi$ becomes zero. Hence, the fabric anisotropy $F$ reaches the critical state $F_{c}$, irrespective of the development of the deviatoric plastic strain $\dot{\epsilon}_{q}^{p}$. Thus, in the critical state $F_{c}=\mathbf{F}_{c}: \mathbf{n}$, which closely resembles the normalisation $A_{c}=1$ by Li and Dafalias (2011). Therefore, the fabric evolution law Eq. (5) is consistent with ACST according to which $F=F_{c}$ at the critical state.

\subsection{Calibration of model parameters}

In the current simulations, three parameters $\left(e_{\Gamma}, \xi\right.$ and $\left.\alpha\right)$ for the critical state line given by Eq. (6) and four parameters $\left(F_{c}, M, h\right.$ and $m$ ) for the fabric evolution law Eq. (5) are required.

As discussed in Zhao and Kruyt (2020), since it is not feasible to separate elastic and plastic strain from the experimental results and elastic strain in granular soils are generally small, the deviatoric plastic strain rate tensor $\dot{\epsilon}_{q}^{p}$ is approximated by the deviatoric strain rate tensor $\dot{\epsilon}_{q}$. The strain increments $\dot{\epsilon}_{q}$ are calculated from the displacement increments of sand particles inside shear bands, using the expression for the strain tensor of Bagi (1996). The accuracy of this method has been established in Durán et al. (2010). Note that such strain increments $\dot{\epsilon}_{q}$ are slightly different from the strain increments in the shear band determined from particle total displacements, since for each strain increment the reference configuration for particle displacement increments is the previous $\mathrm{x}$-ray scan, but not the first $\mathrm{x}$-ray image of the sand sample.

The stress ratio $\eta=q / p$ required in the evolution law Eq. (5) is taken equal to that measured for the whole sample. The reason is that the interparticle contact forces are not measured in the experiments, and hence it is not possible to determine the average stress inside the shear band. This is an assumption to be verified in future studies, using DEM simulations.

To calculate the state parameter $\psi=e-e_{c}(p)$, the void ratio $e$ measured inside shear bands is adopted, whereas the critical state void ratio $e_{c}(p)$ is determined from Eq. (6). Since the experiments for Hostun 
sand involve only two different confining pressures (100 kPa and 400 $\mathrm{kPa}$ ) and those for Caicos ooids involve only one confining pressure $(100 \mathrm{kPa})$, it is not possible to calibrate the three parameters $e_{\Gamma}, \xi$ and $\alpha$. Therefore, the value of the exponent $\alpha=0.9$ that was proposed in $\mathrm{Li}$ (2013) for the macroscopic critical state line of Hostun sand is adopted. For Hostun sand, the other two parameters $\left(e_{\Gamma}\right.$ and $\xi$ ) for the critical state line are determined from the void ratio inside the shear band at the end of the test. For Caicos ooids, $\xi$ is assumed to be the same as for Hostun sand, whereas $e_{\Gamma}$ is directly determined from the critical state void ratio in the shear band. The calibrated parameters for the critical state line are given in Table 2.

For the fabric evolution law, the initial fabric (directly taken from that measured inside shear bands) is used as the initial condition. Since the strain increment (determined by Bagi's method Bagi, 1996) between two $\mathrm{x}$-ray scans is large, it is divided into 100 uniformly spaced strain increments for the numerical integration of the fabric evolution law (note that when the number of strain increments is greater than 10, the simulation results are the same). At intermediate strains (between two xray scans), the stress ratio $\eta$ and the state parameter $\psi$ are interpolated.

By substituting the interpolated deviatoric strain rate tensor $\dot{\epsilon}_{q}$, initial fabric $\mathbf{F}$, stress ratio $\eta$, and state parameter $\psi$ into the fabric evolution law (Eq. (5)), the rate of fabric anisotropy is obtained. For Hostun sand, the parameters are determined from tests HNMWTC02 and HNMWTC05, while HNEA01 is used as a "blind test". The parameters $F_{c}$, $h$ and $m$ used in the fabric evolution law have been obtained by comparing the fabric anisotropy predicted by Eq. (5) with that measured inside shear bands, using a trial-and-error least-squares approach. The optimized parameters are given in Table 2.

\subsection{Model simulations}

Fig. 7 shows the predicted and measured evolution of fabric anisotropy $F$ as a function of the deviatoric strain inside the shear band for the five tests.

Qualitatively, the model simulations are in good agreement with the experimental results. Fabric anisotropy shows a distinct peak (especially for Caicos ooids), which has been well reproduced by the fabric evolution law. Quantitatively, for test HNMWTC02 the deviation between model simulations and experiments has a maximum value of $7.1 \%$ (when the local deviatoric strain $\epsilon_{q}=33.3 \%$ ) and an average value smaller than 5\%. For test HNMWTC05, the maximum deviation is $11.9 \%$ (when $\epsilon_{q}=13.6 \%$ ), and the average deviation is 6\%. For Caicois ooids, the simulations have a maximum deviation of $13.6 \%$ (when $\epsilon_{q}=$ $26.2 \%$ ) for test COEA01 and 9.8\% (when $\in_{q}=29.2 \%$ ) for test COEA04, and an average deviation smaller than $5 \%$ for both tests. Overall, for the four tests used for the calibration of the model parameters, the model predictions agree well with the experiments when the deviatoric strain is smaller than $5 \%$, with deviations smaller than $5 \%$.

For the simulations of HNEA01 (a "blind test", i.e., these test data have not been used in the calibration of the model parameters), the deviations between model simulations and experiments are larger than for the other cases (see black curves in Fig. 7(a)). The average deviation is about $20 \%$, with a maximum value of $35.4 \%$ (when $\epsilon_{q}=28.9 \%$ ). At larger deformations, the fabric evolution law gives larger fabric anisotropy than the one measured in the experiment. A possible reason is that the critical state fabric $\left(F_{c}\right)$ and stress ratio $(M)$ in test HNEA01 are

Table 2

Model parameters used for the critical state line (Eq. (6)) and the fabric evolution law (Eq. (5)).

\begin{tabular}{|c|c|c|c|c|c|c|c|}
\hline \multirow[b]{2}{*}{ Material } & \multicolumn{3}{|c|}{ Critical state line } & \multicolumn{4}{|c|}{ Fabric evolution law } \\
\hline & $e_{\Gamma}$ & $\xi$ & $\alpha$ & $M$ & $F_{c}$ & $h$ & $m$ \\
\hline Hostun Sand & 0.961 & 0.015 & 0.9 & 1.6 & 0.34 & 30 & 0.1 \\
\hline Caicos ooids & 0.822 & 0.015 & 0.9 & 1.5 & 0.33 & 65 & 0.85 \\
\hline
\end{tabular}

very different from those in the two tests that have been used to calibrate the model parameters.

A detailed assessment of the accuracy of the fabric evolution law for fabric anisotropy is hampered by the limited amount of experimental data (with their intrinsic uncertainties): (i) the number of x-ray scans is limited, which makes it difficult to evaluate quantities like void ratio, stress ratio and strain increments at intermediate strain levels, (ii) plastic strains could not be extracted from the experimental data, and therefore these have been taken equal to the total strains, (iii) the number of confining pressure levels considered did not allow for accurate calibration of the critical state line that is required in the fabric evolution law, (iv) the number of grains present in the two observation windows is fairly small, and (v) no data is available on local stresses inside the shear band, and therefore overall, average stresses have been employed.

Overall, the fabric evolution law is capable of reproducing the evolution of fabric anisotropy of real granular soils (rather than the idealised particles used in DEM simulations), and it is to be further evaluated quantitatively by additional experiments with more $\mathrm{x}$-ray scans in future studies.

\section{Conclusions}

Fabric anisotropy is very important to the behaviour of granular soils. The development of evolution laws for fabric has greatly advanced since the formulation of ACST (Li and Dafalias, 2011). In general, experimental data on fabric anisotropy for real granular soils are very limited, especially in the critical state.

Using x-ray tomography measurements, experimental data on fabric anisotropy inside shear bands have been provided for two real granular soils. These data have been used to assess the validity of ACST and the accuracy of a fabric evolution law which was previously developed using data from idealised DEM simulations.

The main findings of this study are:

- Fabric anisotropy inside shear bands is larger than that outside shear bands; this is due to the smaller deformation outside of the shear band, resulting in the development of limited fabric anisotropy.

- The experimental results for both materials are largely consistent with the classical CST.

- For Caicos ooids,fabric anisotropy and the coordination number clearly approach unique values at large strain, irrespective of the initial fabric and void ratio.

- For Hostun sand, the results are less clear, but it seems that fabric anisotropy may be developing toward unique asymptotic values at large strains, although initial fabric anisotropy, void ratio and confining pressure are different.

- Overall, these experimental observations support ACST. The angularity of soil particles has significant impact on the evolution of fabric anisotropy and coordination number: in the tests on rounded Caicos ooids the critical state is approached more rapidly than in the tests on angular Hostun sand.

- The measured evolution of fabric anisotropy inside shear bands is fairly well predicted by the evolution law proposed in Zhao and Kruyt (2020), at least from a qualitative standpoint.

The obvious (and necessary) extension of this study should include more detailed information on fabric evolution and the critical state, which can be obtained by performing many more x-ray scans during a test, and shearing the specimens to larger strains. Also, a wider range of confinement pressures should be investigated.

For future studies, other important issues related to the evolution of fabric anisotropy of granular soils could also be investigated. In this study, the fabric tensor is based on contact normal orientations; it would be of interest to also examine the evolution of other fabric tensors. In the experiments, the effects of particle shape and possible particle breakage 

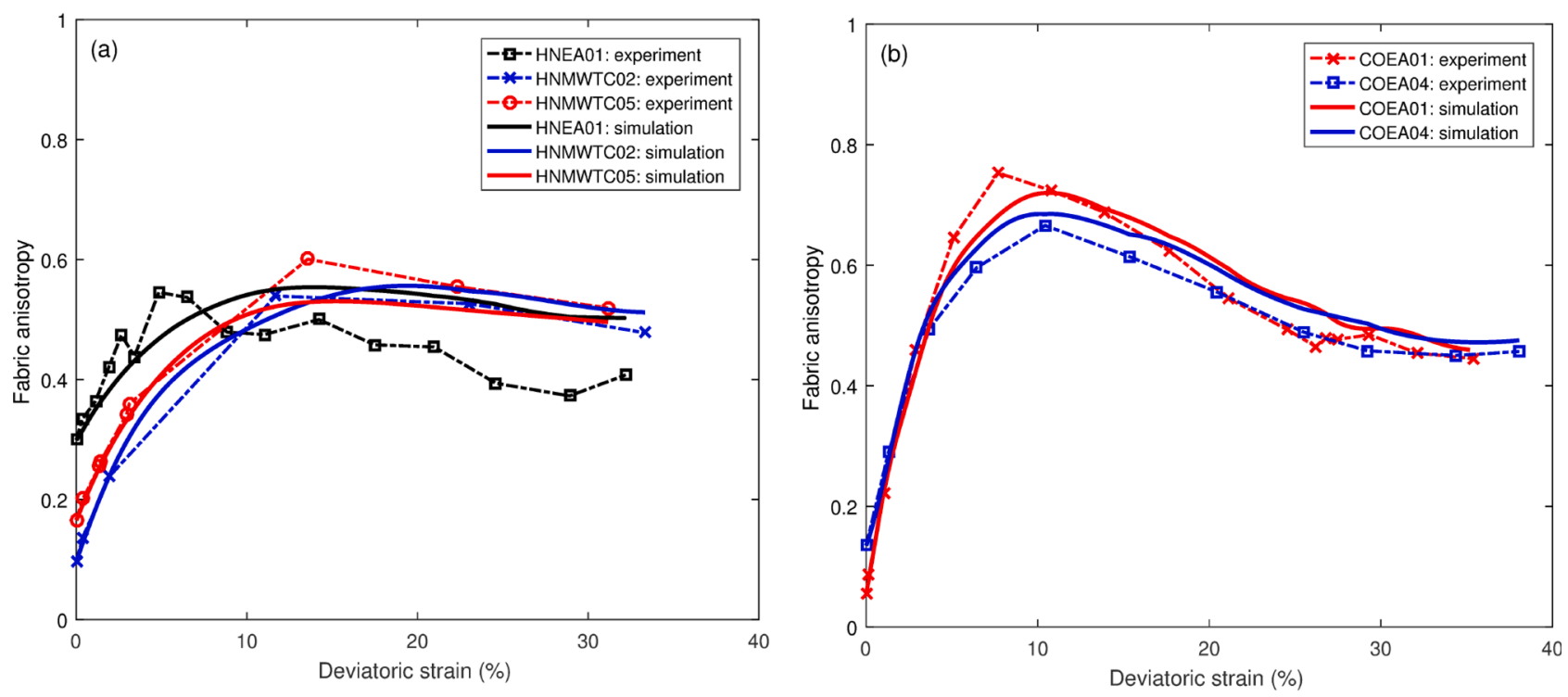

Fig. 7. Comparison of predicted and measured evolution of fabric anisotropy within shear bands: (a) Hostun sand; (b) Caicos ooids.

on fabric evolution could also be measured. The influence of loading directions could also be investigated, by performing cyclic loading with larger amplitudes or rotational shearing. Finally, in the evolution law for fabric anisotropy (Zhao and Kruyt, 2020), it is assumed that the rate of fabric change is proportional to the plastic strain rate. This is a strong assumption that can (and should) be verified by analysing the experimental results from x-ray tomography.

\section{CRediT authorship contribution statement}

Chao-Fa Zhao: Formal analysis, Data curation, Writing - review \& editing. Gustavo Pinzón: Formal analysis, Data curation, Writing original draft. Max Wiebicke: Formal analysis, Data curation, Writing original draft. Edward Andò: Formal analysis, Data curation, Methodology, Writing - original draft, Supervision. Niels P. Kruyt: Conceptualization, Methodology, Writing - review \& editing, Supervision. Gioacchino Viggiani: Conceptualization, Methodology, Writing original draft, Supervision.

\section{Declaration of Competing Interest}

The authors declare that they have no known competing financial interests or personal relationships that could have appeared to influence the work reported in this paper.

\section{Acknowledgments}

The authors thank Jacques Desrues and Pascal Charrier from Laboratoire 3SR Grenoble as well as Ivo Herle from the TU Dresden for stimulating discussions and technical help.

This project has received funding from the European Union's Horizon 2020 research and innovation program under the Marie Skłodowska-Curie grant agreement No. 812638 (CALIPER).

The first author acknowledges financial support from the European Union's Horizon 2020 research and innovation program under the Marie Skłodowska-Curie grant agreement No. 832405 (ICARUS).

The third author acknowledges funding from the German Research Foundation (DFG) (Grant No. 254872581).

The authors from Grenoble acknowledge financial support from European Research Council under the European Union's Seventh Framework Program FP7-ERC-IDEAS Advanced Grant Agreement No. 290963 (SOMEF). Laboratoire 3SR is part of the LabEx Tec 21
(Investissements d'Avenir - Grant Agreement No. ANR-11-LABX-0030).

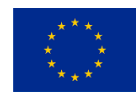

References

Andò, E., 2013. Experimental investigation of microstructural changes in deforming granular media using x-ray tomography, Ph.D. thesis, Université Grenoble Alpes.

Andò, E., Viggiani, G., 2018. On the ease of experimental access to deformation entities in granular assemblies. Rivista Italiana di Geotecnica 52, 44-51.

Andò, E., Viggiani, G., Hall, S., Desrues, J., 2013. Experimental micro-mechanics of granular media studied by x-ray tomography: recent results and challenges. Géotechnique Lett. 3, 142-146.

Ando, E., Dijkstra, J., Roubin, E., Dano, C., Boller, E., 2019. A peek into the origin of creep in sand. Granular Matter 21, 11.

Bagi, K., 1996. Stress and strain in granular assemblies. Mech. Mater. 22, 165-177.

Barreto, D., O'Sullivan, C., 2012. The influence of inter-particle friction and the intermediate stress ratio on soil response under generalised stress conditions. Granular Matter 14, 505-521.

Beare, R., Lehmann, G., 2006. The watershed transform in itk-discussion and new developments. Insight J. 92, 1-24.

Been, K., Jefferies, M., 1985. A state parameter for sands. Géotechnique 35, 99-112.

Calvetti, F., Combe, G., Lanier, J., 1997. Experimental micromechanical analysis of a 2D granular material: relation between structure evolution and loading path. Mech. Cohesive-frictional Mater.: Int. J. Exp., Modell. Comput. Mater. Struct. 2, 121-163.

Cambou, B., Jean, M., Radjaï, F., 2013. Micromechanics of Granular Materials. John Wiley \& Sons.

Chantawarangul, K., 1993. Numerical simulations of three-dimensional granular assemblies, Ph.D. Thesis, Dept. of Civil Engineering, Univ. of Waterloo 219.

Christoffersen, J., Mehrabadi, M.M., Nemat-Nasser, S., 1981. A micromechanical description of granular material behavior. J. Appl. Mech. 48, 339-344.

Cundall, P.A., Strack, O.D.L., 1979. A discrete numerical model for granular assemblies. Géotechnique 29, 47-65.

Desrues, J., Chambon, R., Mokni, M., Mazerolle, F., 1996. Void ratio evolution inside shear bands in triaxial sand specimens studied by computed tomography. Géotechnique 46, 529-546.

Drescher, A., de Josselin de Jong, G., 1972. Photoelastic verification of a mechanical model for the flow of a granular material. J. Mech. Phys. Solids 20, 337-340.

Durán, O., Kruyt, N.P., Luding, S., 2010. Analysis of three-dimensional micro-mechanical strain formulations for granular materials: evaluation of accuracy. Int. J. Solids Struct. 47, 251-260.

Fang, H., Shen, Y., Zhao, Y., 2019. Multishear bounding surface modelling of anisotropic sands accounting for fabric and its evolution. Comput. Geotech. 110, 57-70.

Fonseca, J., O'Sullivan, C., Coop, M.R., Lee, P., 2013. Quantifying the evolution of soil fabric during shearing using directional parameters. Géotechnique 63, 487-499.

Fu, P., Dafalias, Y.F., 2011. Fabric evolution within shear bands of granular materials and its relation to critical state theory. Int. J. Numer. Anal. Meth. Geomech. 35, 1918-1948.

Fu, P., Dafalias, Y.F., 2015. Relationship between void- and contact normal-based fabric tensors for 2D idealized granular materials. Int. J. Solids Struct. 63, 68-81.

Gao, Z., Zhao, J., 2017. A non-coaxial critical-state model for sand accounting for fabric anisotropy and fabric evolution. Int. J. Solids Struct. 106, 200-212. 
Gao, Z., Zhao, J., Li, X.-S., Dafalias, Y.F., 2014. A critical state sand plasticity model accounting for fabric evolution. Int. J. Numer. Anal. Meth. Geomech. 38, 370-390.

Grady, L., 2006. Random walks for image segmentation. In: IEEE Transactions on Pattern Analysis and Machine Intelligence. vol. 28.

Hall, S.A., Bornert, M., Desrues, J., Pannier, Y., Lenoir, N., Viggiani, G., Bésuelle, P. 2010. Discrete and continuum analysis of localised deformation in sand using $\mathrm{x}$-ray $\mu \mathrm{CT}$ and volumetric digital image correlation. Géotechnique 60, 315-322.

Huang, X., Hanley, K., O'Sullivan, C., Kwok, C., Wadee, M., 2014. DEM analysis of the influence of the intermediate stress ratio on the critical-state behaviour of granula materials. Granular Matter 16, 641-655.

Imseeh, W.H., Druckrey, A.M., Alshibli, K.A., 2018. 3D experimental quantification of fabric and fabric evolution of sheared granular materials using synchrotron microcomputed tomography. Granular Matter 20, 24.

Jiang, M., Zhang, A., Li, T., 2019. Distinct element analysis of the microstructure evolution in granular soils under cyclic loading. Granular Matter 21, 39.

Kanatani, K.-I., 1984. Distribution of directional data and fabric tensors. Int. J. Eng. Sci. $22,149-164$.

Karapiperis, K., Harmon, J., Andò, E., Viggiani, G., Andrade, J., 2020. Investigating the incremental behavior of granular materials with the level-set discrete element method. J. Mech. Phys. Solids 144, 104103.

Kawamoto, R., Andò, E., Viggiani, G., Andrade, J.E., 2018. All you need is shape: Predicting shear banding in sand with LS-DEM. J. Mech. Phys. Solids 111, 375-392.

Kruyt, N.P., 2003. Contact forces in anisotropic frictional granular materials. Int. J. Solids Struct. 40, 3537-3556.

Kruyt, N.P., 2012. Micromechanical study of fabric evolution in quasi-static deformation of granular materials. Mech. Mater. 44, 120-129.

Kruyt, N.P., Rothenburg, L., 1996. Micromechanical definition of the strain tensor for granular materials. J. Appl. Mech. 63, 706-711.

Kruyt, N.P., Rothenburg, L., 2014. On micromechanical characteristics of the critical state of two-dimensional granular materials. Acta Mech. 225, 2301-2318.

Kruyt, N.P., Rothenburg, L., 2016. A micromechanical study of dilatancy of granular materials. J. Mech. Phys. Solids 95, 411-427.

Kruyt, N.P., Rothenburg, L., 2019. A strain-displacement-fabric relationship for granular materials. Int. J. Solids Struct. 165, 14-22.

Lam, W.-K., Tatsuoka, F., 1988. Effects of initial anisotropic fabric and $\sigma 2$ on strength and deformation characteristics of sand. Soils Found. 28, 89-106.

Lashkari, A., Latifi, M., 2008. A non-coaxial constitutive model for sand deformation under rotation of principal stress axes. Int. J. Numer. Anal. Meth. Geomech. 32, $1051-1086$

Li, G., 2013. Étude de l'influence de l'étalement granulometrique sur le comportement mécanique des materiaux granulaires, Ph.D. thesis, Ecole Centrale de Nantes.

Li, X., 2016. Internal structure quantification for granular constitutive modeling. J. Eng. Mech. 143, C4016001.

Li, X.S., Dafalias, Y.F., 2000. Dilatancy for cohesionless soils. Géotechnique 50, 449-460.

Li, X.S., Dafalias, Y.F., 2011. Anisotropic critical state theory: role of fabric. J. Eng. Mech. 138, 263-275.

Li, X.S., Dafalias, Y.F., 2015. Dissipation consistent fabric tensor definition from DEM to continuum for granular media. J. Mech. Phys. Solids 78, 141-153.

Li, X., Li, X.-S., 2009. Micro-macro quantification of the internal structure of granular materials. J. Eng. Mech. 135, 641-656.

Li, X., Yu, H.S., 2013. On the stress-force-fabric relationship for granular materials. Int. J. Solids Struct. 50, 1285-1302.

Li, X., Yu, H.S., 2014. Fabric, force and strength anisotropies in granular materials: a micromechanical insight. Acta Mech. 225, 2345-2362.

Liao, C.-L., Chang, T.-P., Young, D.-H., Chang, C.S., 1997. Stress-strain relationship for granular materials based on the hypothesis of best fit. Int. J. Solids Struct. 34, 4087-4100.

Mirghasemi, A.A., Rothenburg, L., Matyas, E.L., 1995. Numerical simulations of assemblies of two-dimensional polygon-shaped particles. Soils Found. 37, 43-52.

Nadimi, S., Fonseca, J., 2018. A micro finite-element model for soil behaviour: numerical validation. Géotechnique 68, 364-369.

Nakata, Y., Hyodo, M., Murata, H., Yasufuku, N., 1998. Flow deformation of sands subjected to principal stress rotation. Soils Found. 38, 115-128.

Nemat-Nasser, S., 2000. A micromechanically-based constitutive model for frictional deformation of granular materials. J. Mech. Phys. Solids 48, 1541-1563.

Nguyen, N.S., Magoariec, H., Cambou, B., Danescu, A., 2009. Analysis of structure and strain at the meso-scale in two-dimensional granular materials. Int. J. Solids Struct. 46, 3257-3271.

Nübel, K., Rothenburg, L., 1996. Particle shape effects in stress-force-fabric relationships for granular media. J. Mech. Behav. Mater. 7, 219-233.

Oda, M., 1972. Initial fabrics and their relations to mechanical properties of granular material. Soils Found. 12, 17-36.

Oda, M., 1982. Fabric tensor for discontinuous geological materials. Soils Found. 22, 96-108.

Oda, M., Nakayama, H., 1988. Introduction of inherent anisotropy of soils in the yield function. In: Studies in Applied Mechanics, vol. 20. Elsevier, pp. 81-90.

Oda, M., Koishikawa, I., Higuchi, T., 1978. Experimental study of anisotropic shear strength of sand by plane strain test. Soils Found. 18, 25-38.

Oda, M., Konishi, J., Nemat-Nasser, S., 1982. Experimental micromechanical evaluation of strength of granular materials: effects of particle rolling. Mech. Mater. 1, 269-283.

Oda, M., Nemat-Nasser, S., Konishi, J., 1985. Stress-induced anisotropy in granular masses. Soils Found. 25, 85-97.

Ouadfel, H., Rothenburg, L., 2001. Stress-force-fabric relationship for assemblies of ellipsoids. Mech. Mater. 33, 201-221.
Petalas, A.L., Dafalias, Y.F., Papadimitriou, A.G., 2019a. SANISAND-FN: An evolving fabric-based sand model accounting for stress principal axes rotation. Int. J. Numer. Anal. Meth. Geomech. 43, 97-123.

Petalas, A.L., Dafalias, Y.F., Papadimitriou, A.G., 2019b. SANISAND-F: Sand constitutive model with evolving fabric anisotropy. Int. J. Solids Struct.

Pietruszczak, S., Pande, G.N., 2001. Description of soil anisotropy based on multilaminate framework. Int. J. Numer. Anal. Meth. Geomech. 25, 197-206.

Reynolds, O.C., 1885. On the dilatancy of media composed of rigid particles in contact. Phil. Mag. 20, 469-481.

Rorato, R., Arroyo, M., Andò, E., Gens, A., 2019. Sphericity measures of sand grains. Eng. Geol. 254, 43-53.

Roscoe, K.H., Schofield, A.N., Wroth, C., 1958. On the yielding of soils. Géotechnique 8, 22-53.

Rothenburg, L., Bathurst, R., 1989. Analytical study of induced anisotropy in idealized granular materials. Géotechnique 39, 601-614.

Rothenburg, L., Bathurst, R.J., 1993. Micromechanical effects in plane assemblies of elliptical particles. Mech. Mater. 16, 141-152.

Rothenburg, L., Kruyt, N.P., 2004. Critical state and evolution of coordination number in simulated granular materials. Int. J. Solids Struct. 41, 5763-5774.

Rowe, P.W., 1962. The stress-dilatancy relation for static equilibrium of an assembly of particles in contact. Proc. Roy. Soc. London A 264, 500-527.

Satake, M., 1978. Constitution of mechanics of granular materials through the graph theory. In: Proceedings of the U.S.-Japan Seminar on Continuum Mechanical and Statistical Approaches in the Mechanics of Granular Materials, Sendai, pp. 47-62.

Schofield, A., Wroth, P., 1968. Critical state soil mechanics. volume 310, McGraw-Hill London.

Shi, J., Guo, P., 2018. Induced fabric anisotropy of granular materials in biaxial tests along imposed strain paths. Soils Found. 58, 249-263.

Shi, J., Guo, P., 2018. Fabric evolution of granular materials along imposed stress paths. Acta Geotech. 13, 1341-1354.

Shi, J., Guo, P., Stolle, D., 2018. Noncoaxiality between fabric and stress in twodimensional granular materials. J. Eng. Mech. 144, 04018092.

Stamati, O., Andò, E., Roubin, E., Cailletaud, R., Wiebicke, M., Pinzon, G., Couture, C., Hurley, R.C., Caulk, R., Caillerie, D., et al., 2020. spam: Software for practical analysis of materials. J. Open Source Softw. 5, 2286.

Sun, J., Sundaresan, S., 2011. A constitutive model with microstructure evolution for flow of rate-independent granular materials. J. Fluid Mech. 682, 590-616.

Tatsuoka, F., Nakamura, S., Huang, C., Tani, K., 1990. Strength anisotropy and shear band direction in plane strain tests of sand. Soils Found. 30, 35-54.

Thornton, C., Barnes, D.J., 1986. Computer simulated deformation of compact granular materials. Acta Mech. 64, 45-61.

Tian, Y., Yao, Y.-P., 2018. Constitutive modeling of principal stress rotation by considering inherent and induced anisotropy of soils. Acta Geotech. 1-13.

Tsuchikura, T., Satake, M., 2001. A consideration on the statistical analysis of particle packing using loop tensors. In: Powders and Grains 2001, Swets \& Zeitlinger, pp. 29-32.

Viggiani, G., Tengattini, A., 2019. Recent developments in laboratory testing of geomaterials with emphasis on imaging, in. In: Proceedings of the XVII European Conference on Soil Mechanics and Geotechnical Engineering, Reykjavík, Iceland.

Wan, R.G., Guo, P.J., 2004. Stress dilatancy and fabric dependencies on sand behavior. J. Eng. Mech. 130, 635-645.

Wan, R., Pouragha, M., 2015. Fabric and connectivity as field descriptors for deformations in granular media. Continuum Mech. Thermodyn. 27, 243-259.

Wang, R., Fu, P., Zhang, J.-M., Dafalias, Y.F., 2017. Evolution of various fabric tensors for granular media toward the critical state. J. Eng. Mech. 143, 04017117.

Wang, R., Cao, W., Zhang, J.-M., 2019. Dependency of dilatancy ratio on fabric anisotropy in granular materials. J. Eng. Mech. 145, 04019076.

Wang, R., Dafalias, Y.F., Fu, P., Zhang, J.-M., 2020. Fabric evolution and dilatancy within anisotropic critical state theory guided and validated by DEM. Int. J. Solids Struct. 188-189, 210-222.

Wiebicke, M., 2020. Experimental analysis of the evolution of fabric in granular soils upon monotonic loading and load reversals, Ph.D. thesis, Technische Universität Dresden and Université Grenoble Alpes. https://nbn-resolving.org/urn:nbn:de:bs z:14-qucosa2-715783.

Wiebicke, M., Andò, E., Herle, I., Viggiani, G., 2017. On the metrology of interparticle contacts in sand from x-ray tomography images. Meas. Sci. Technol. 28, 124007.

Wiebicke, M., Andò, E., Šmilauer, V., Herle, I., Viggiani, G., 2019. A benchmark strategy for the experimental measurement of contact fabric. Granular Matter 21, 54.

Wiebicke, M., Andò, E., Viggiani, G., Herle, I., 2020. Measuring the evolution of contact fabric in shear bands with X-ray tomography. Acta Geotech. 15, 79-93.

Woo, S.I., Salgado, R., 2015. Bounding surface modeling of sand with consideration of fabric and its evolution during monotonic shearing. Int. J. Solids Struct. 63 277-288.

Yang, Z.X., Wu, Y., 2016. Critical state for anisotropic granular materials: a discrete element perspective. Int. J. Geomech. 17, 04016054.

Yang, Z.X., Li, X.S., Yang, J., 2007. Undrained anisotropy and rotational shear in granular soil. Géotechnique 57, 371-384.

Yang, Z.X., Li, X.S., Yang, J., 2008. Quantifying and modelling fabric anisotropy of granular soils. Géotechnique 58, 237-248.

Yang, Z.X., Yang, J., Wang, L.Z., 2013. Micro-scale modeling of anisotropy effects on undrained behavior of granular soils. Granular Matter 15, 557-572.

Yang, Z.X., Xu, T.T., Chen, Y.N., 2018. Unified modeling of the influence of consolidation conditions on monotonic soil response considering fabric evolution. J. Eng. Mech. 144, 04018073. 
Yoshimine, M., Ishihara, K., Vargas, W., 1998. Effects of principal stress direction and intermediate principal stress on undrained shear behavior of sand. Soils Found. 38 , 179-188.

Yuan, R., Yu, H.-S., Yang, D.-S., Hu, N., 2019. On a fabric evolution law incorporating the effects of b-value. Comput. Geotech. 105, 142-154.
Zhao, J., Guo, N., 2013. Unique critical state characteristics in granular media considering fabric anisotropy. Géotechnique 63, 695-704.

Zhao, C.-F., Kruyt, N.P., 2020. An evolution law for fabric anisotropy and its application in micromechanical modelling of granular materials. Int. J. Solids Struct. 196-197, $53-66$. 